\title{
СТРУКТУРНАЯ МОДЕРНИЗАЦИЯ РОССИЙСКОЙ ЭКОНОМИКИ: ЦЕЛИ И УСТАНОВКИ *
}

\author{
(c) 2021 Курнышева Ирина Романовна \\ главный научный сотрудник, доктор экономических наук, заведующий сектором \\ Институт экономики РАН, Россия, Москва \\ E-mail: kurnisheva@yandex.ru
}

Рассматриваются: отраслевая структура валовой добавленной стоимости как исходный компонент адаптивной установки готовности к будущему; установки и риски выбора структурных приоритетов; концептуальные основы структурной модернизации российской экономики; функции и цели цифровых технологий как «катализатора» экономического роста перспективного тренда России.

Ключевые слова: национальные цели, цифровая экономика, структура, технологии, устойчивое развитие, системообразующие предприятия

Актуальность статьи вызвана необходимостью противостоять усилению давления старых и появлению новых вызовов структурному и устойчивому развитию национальной экономики. Цель статьи проанализировать цели и установки структурной трансформации российской экономики, на базе процессов цифровизации предложить рекомендации по их модернизации. Основной метод исследования базируется на аналитическом использовании совокупности отечественных и зарубежных теоретических, нормативных, статистических и литературных источников по макроэкономике, структурной, технологической политике, диджитализации экономики и общества, конкурентоспособности. В основе методологии лежит структурный анализ. Он позволяет предвидеть перспективные тенденции, цели и риски структурной трансформации российской экономики, возможности прагматичной инклюзии, новых для нее, цифровых технологий - в этом состоит научная новизна статьи.

Для осуществления проектов по структурной модернизации российской экономики и формированию новой модели экономического роста, решение следует искать не только на путях экономического роста, но и в причинах долгосрочной устойчивости отраслевых структурных параметров. Готова ли российская экономика к структурным трансформациям?

С начала 90-х годов прошлого века в России начались рыночные реформы. В 2000-м году Россию признали страной с рыночной экономикой. Но до сих пор рыночные институты и механизмы, например конкуренция, во многом регулирующие структурные трансформации, не органичны нашей экономике.

Бурно развернувшиеся в мировой практике научные и технологические сдвиги, процессы цифровой трансформации адекватно не воспринимаются российской экономикой. Это одновременно является и причиной, и следствием длительного сохранения сложившихся инерционных для российской экономики тенденций, пропорций, диспропорций и институтов структурного развития.

Перспективы мировой и российской экономики, прежде всего, определяются, готовностью к изменениям.

Готовность к будущему - одно из обязательных современных условий, необходимых к переходу к качественным структурным трансформациям. В методологии рейтинговой практики разработанной (WDC) IMD [1]. Готовность K будущему определяется тремя составляющими: Адаптивными установками - Гибкостью бизнеса - ИТ интеграцией. Адаптивные установки это, те факторы и рамки, которые помогают нарождающимся изменениям приспособиться $\mathrm{k}$ существующим условиям, параметрам. В данной статье готовность российской экономики к будущему рассматривается с позиций структурных

\footnotetext{
* Статья подготовлена по материалам исследования темы государственного задания: «Формирование научнотехнологического контура и институциональной модели ускорения экономического роста в Российской Федерации»
} 
параметров, как одного из элементов адаптации.

Темпы и направленность тенденций структур выпуска и валовой добавленной стоимости по тем отраслям экономики, которые, на мой взгляд, более всего определяют готовность к будущему за 2018-2020 гг. выразились в следующем.

За три исследуемых года, 2018-2020 гг., в структуре выпуска и валовой добавленной стоимости (ВДС), как показывают данные Росстата [2.c.81-82], наблюдались структурные сдвиги, носившие «мини», но актуальный характер. Данные этих лет не вполне сопоставимы с данными за предыдущие годы тем, что содержат изменения, связанные с внедрением практики международной методологии расчетов многих показателей, категорий и позиций. Поэтому их сравнение по абсолютной величине неправомерно. Анализируя тенденции изменения структуры выпуска и валовой добавленной стоимости по отдельным отраслям экономики (в текущих основных ценах; в \% к итогу), с предыдущим периодом можно отметить, во-первых, наибольший удельный вес в выпуске (26,0\%) и (чуть более $14 \%$ ) в ВДС остается за обрабатывающими производствами, Во-вторых, позитивная динамика долей в общем объеме ВДС в текущих основных ценах происходила в отраслях: добыча полезных ископаемых - снижение на - 0,6 пп; обрабатывающие производства рост на +0,4 пп, образование, деятельность в области здравоохранения и социальных услуг. А также в деятельности в области информации и связи (+0,3 пп), деятельности финансовой и страховой, государственном управлении и обеспечении военной безопасности; социальном обеспечении. Лидером структурных сдвигов были: государственное управление и обеспечение военной безопасности; социальное обеспечение +0,8пп).

Начиная с 2020 г, одной из доминирующих характерных черт мировой и российской экономики, становится более высокая степень неопределенности перспектив и рисков, особенно коммерческих. Однако, «Несмотря на объектив- ные текущие трудности, наши долгосрочные ориентиры остаются неизменными», подчеркивал президент России, указывая, что предстоит учитывать факторы и обстоятельства, связанные с пандемией и экономическим кризисом»*. Помимо трудностей, связанных с пандемией и экономическим кризисом, серьезная проблема и риск в средне и долгосрочной перспективе РФ состоит, на мой взгляд, в выборе формата, критериев и оснований для поддержки структурных приоритетов, формирующих готовность к будущему, а именно - опасность выбора неверного варианта пути развития. Этот выбор может усугубить неконкурентоспособное социальноэкономическое, технологическое положение страны, нарушить сформировавшуюся, и так высоко ценимую, и трудно завоеванную макроэкономическую стабильность, углубить диспропорциональность, зависимость и отставание от более развитых стран.

В соответствии с предложениями федеральных органов исполнительной власти для поддержки российской экономики, отдельных отраслей и повышения ее устойчивости было принято решение о поддержке системообразующих организаций**. Оно было опубликовано в Постановлении Правительства РФ от 10 мая 2020 г. N 651 «О мерах поддержки системообразующих организаций» [4]от 12 мая 2020 г. Полный перечень системообразующих компаний и организаций РФ, утвержденный правительственной комиссией на март 2020 г. включал 646 компаний [5]. Список этот постоянно обновляется за счет включения новых организаций. По состоянию на 03.12.2020 г. количество предприятий, входящих в список, нуждающихся в поддержке составляло 1392. Таким образом, организационные и экономические последствия пандемии короновируса и кризиса вкупе, привели к более серьезным последствиям, чем ранее предполагалось. Более всего увеличилось число предприятий Министерства промышленности и торговли России было 305, а стало 591, т.е, 286 организациям потребовалась финансо-

\footnotetext{
* Указ Президента Российской Федерации от 21.07.2020 г. № 474 О национальных целях развития Российской Федерации на период до 2030 года [электронный ресурс]//резидент России - режим доступа http://kremlin.ru/ acts/news/63728.

** Системообразующие предприятия, это одно из - установочных понятий, сохранившееся с советских времен. К ним относится система предприятий функционирование и результаты деятельности, которых, имеют государственное финансово - экономическое, социальное, военное и пр. значение. Они значимы и распространены по всей территории страны обеспечивая, в определенной мере, пространственную устойчивость и часто выступают в роли монополистов.
} 
вая поддержка. На втором месте- Министерство транспорта России. Количество системообразующих организаций этого ведомства по состоянию на 28.07.2021 г. составило 189 против 68 по состоянию на 28.07.2021 г. Число предприятий Минкомсвязи выросло с 21 до 102. Но были и исключения. В Министерстве энергетики число организаций, нуждающихся в поддержке, по мнению ФОИВ сократилось с 73 до 47. Появились новые министерства и ведомства. Общее количество организаций этих ведомств -177 , в том числе ГК «Росатом» -50 ; ГК «Роскосмос» -25.

Для сравнения - при утверждении списка 25 декабря 2008 г. в него было включено 304 [6] предприятий, то есть почти в 5 раз меньше, чем в 2020 г.

Из этой информации можно сделать много выводов, но исходя из проблематики статьи, отметим две: все меньше и меньше остается пространства для рыночной и конкурентной среды и конкурентных отношений; долгосрочные структурные приоритетные трансформации пока четко не просматриваются.

Подключение экономики РФ к принципам Концепции устойчивого развития в формате Повестки дня в области устойчивого развития на период до 2030 года предполагает изменение акцентов при структуризации целей макроэкономической политики. Основанием для этого стала утвержденная 07.2017 года Генеральной Ассамблеей $\mathrm{OOH}$ система глобальных показателей достижения семнадцати взаимосвязанных и неразделимых целей и задач в области устойчивого развития, которой следуют все государства. Более чем треть целей, содержащихся в этом концептуальном документе, направлена на повышение уровня и качества жизни населения планеты. Четыре из целей регулируют взаимодействие экономического и инновационного развития. Три цели формируют экологическую составляющую повестки дня и одна - институциональную [7].

Концептуальным выражением средне- и долгосрочной современной макроэкономической политики РФ выступает подписанный Президентом России В.Путиным «Указ о национальных целях развития страны до 2030 года» [8].

Установленные в Указе целевые показатели, конкретизируют поставленные цели и определяют их как планируемые измеряемые конечные результаты решения проблем перспективного социально-экономического развития. Цели, в данном документе: соответствует особенностям текущего и предстоящего периодов времени при их реализации; наиболее актуальные выражены в конкретном количественном, числовом показателе.

В такой постановке задач и целей преобразования структурных параметров перспективного тренда России можно проследить определенную аналогию с мировыми. В опубликованном Указе национальные цели развития страны до 2030 года разработаны в духе и русле созданной и принятой Межучрежденческой и экспертной группой (МЭГ-ЦУР) программе по показателям достижения целей в области устойчивого развития. В ней первоочередными и приоритетными целями обозначены социальные: сохранение населения, здоровье и благополучие людей, возможности для самореализации и развития талантов, комфортная и безопасная среда для жизни.

Большая часть целей средне и долгосрочного развития нашей страны также посвящена решению социальных проблем, из пяти выдвинутых национальных целей три имеют социальную направленность. Таким образом, Президентом России поставлена задача поднять не только уровень, но и качество жизни населения, привести их в соответствие с новыми задачами и требованиями времени.

Экономическим целям посвящен пункт «достойный, эффективный труд и успешное предпринимательство», охватывающий почти все актуальные и острые проблемы. В частности, предусмотрено обеспечение темпа роста валового внутреннего продукта страны выше среднемирового при сохранении макроэкономической стабильности. Последнее условие является почти обязательным.

Отдельным тезисом выделена национальная цель «цифровая трансформация».

Мотивационным базисом и содержанием стратегической структурной технологической модернизации российской экономики становится формирование новой модели экономического роста на платформе национальной цели «Цифровая трансформация».

На цифровые технологии в настоящий момент рассчитывают, как на «драйвер» экономического роста из разряда новой парадигмальной действительности. При их использовании и широком распространении в реальном секторе экономики, финансовой, социальной, ин- 
дивидуальной сфере [9], в управлении на всех иерархических уровнях предполагают преодолеть инертность и инерционность экономики, вызвать рост технологического уровня, и мотиваций на создание новых индустрий, бизнесмоделей, рынков.

Целевые показатели поставленной цели в том виде, в котором они обозначены, по достижению ключевыми отраслями экономики и социальной сферы, а также государственного управления «цифровой зрелости» (термин количественно и понятийно не определен) вполне достижимы за предусмотренный временной период. Хотя предприниматели отечественного ИТ-сектора экономики в ходе первого обследования PwC и ABBYY «Digital IQ Russia», низко оценили уровень своей цифровой зрелости 2,8 баллов сходя из пятибалльной шкалы,[9] отмечая, что место России в рейтинге международной цифровой конкурентоспособности нестабильно и не очень высоко. 38 место было зафиксировано в 2019г и 43 - в 2020г по расчетам Institute of Management Development, IMD.[10] При этом мировые аналитические агентства расценивают позиции России в процессе диджитализации вполне оптимистично. В рейтинге 2020г, по информации собранной аналитиками HARVARD BISNESS REVIEW[9] и материалов Digital Planet Школы Флетчера, была произведена оценка 90 экономик мира по двум укрупненным показателям: текущее состояние цифровизации в стране и ее скорость за 12 лет - с 2008-го по 2019 гг. По итогам этой оценки страны были систематизированы в четыре группы Лидеры, Перспективные, Замедляющиеся, Проблемные. Россия, по мнению этих аналитиков, входит в группу стран Перспективные, благодаря стремительной диджитализации, при низком ее исходном уровне.

Ни благоприятные условия первого десятилетия 2000-х годов, ни кризисные события последних лет не обладали стимулами к структурным, технологическим трансформациям. Предстоит поиск недостающего звена. Потенциально ключевыми факторами может послужить изменение акцентов в системе адаптивных установок готовности российской экономики к будущему и создание всесторонней поддержки мотивационного решения проблемы особенно, творческого.

\section{Библиографический список}

1. https://www.imd.org/centers/world-competitiveness-center/rankings/world-digital-competitiveness/

2. Россия в цифрах. 2021: Крат.стат.сб./Росстат- М., 2021-275с. Сс81-82

3. Указ Президента Российской Федерации от 21.07 .2020 г. № 474 О национальных целях развития Российской Федерации на период до 2030 года [электронный ресурс]//Президент России - режим доступа http:// kremlin.ru/acts/news/63728

4. https://data.economy.gov.ru/analytics/facilities/enlist/criteria / Министерство экономического развития

5. https://www.law.ru/article/22819-sistemoobrazuyushchie-organizatsii-perechen ЮРИСТ компании Практический журнал для юристов

6. rbc.ru (25 декабря 2008)LENTA.RU

7. О целях устойчивого развития https://rosstat.gov.ru/sdg

8. http://www.kremlin.ru/events/president/news/63728 Президент России

9. https://hbr-russia.ru/innovatsii/trendy/865315 HARVARD BISNESS REVIEW Россия инновации/тренды

10. The IMD World Competitiveness Ranking. [электронный ресурс $\left.{ }^{\mathrm{c}}\right] /$ по версии Института менеджмента (Institute of Management Development).режим доступа https://gtmarket.ru/ratings/imd-world-competitiveness-ranking. 